\title{
Super vision
}

\section{John Launer}

My main educational role these days is to organise and lead courses in supervision for consultants and senior trainees. We address topics such as how to help high fliers to achieve their potential, how to support doctors in difficulty, and how to challenge ones who are behaving inappropriately. We run training in a variety of formats including one-day introductory workshops, three-day courses and a professional certificate course extending over a whole year. We advertise through websites and by email. Generally the courses fill up very quickly, so that we often have a waiting list for places.

Recently we sent out an email to consultants in London, announcing that places were still available on our next threeday course. In response, one consultant wrote to us as follows: "Do people really need three days to learn how to supervise? I mean, can any clinician afford this much time off for a course such as this? I can understand a clinically based update course taking a day or two, but supervision is not exactly rocket science, is it? Sure, some people do it badly, I know, but that is more likely to be down to poor attitude, or pressure of time etc, rather than any deficiency of knowledge or skills. Anyway, I would contend that $90 \%$ of good supervision is down to good clinical knowledge."

\section{WIDESPREAD HOSTILITY}

I was taken aback. However, I was grateful that the writer had expressed so clearly what many of his colleagues feel, but are normally too polite to say. There is in fact widespread hostility, especially among senior hospital doctors, to the idea that supervision is a skill needing to be learned or taught. Other specialities within medicine, and other professions, do not necessarily see things the same way. General practitioners, for example, have to complete the equivalent of a postgraduate certificate in education before they are allowed to take on a trainee in their practice. Junior psychiatrists usually meet their supervisors for an hour or so every week to discuss complex or troubling clinical cases. In other mental health professions, regular supervision is regarded

Correspondence to: Dr John Launer, London Deanery, Stewart House, London WC1B 5DN, UK; jlauner@ londondeanery.ac.uk as a form of oxygen, necessary not only for learners but for established practitioners as well. In areas such as psychology and social work, there are not only courses in supervision but also diplomas and degrees. Some fields have books and even journals devoted to the subject.

There are a number of reasons why many people in the hospital-based specialities seem to take such a sceptical view of supervision skills. For a start, there is widespread confusion of supervision with purely technical training. Some consultants, such as the one who wrote to me, seem to believe that the only professional attributes they need in order to be good supervisors are sound clinical judgement together with a willingness to give trainees direct information and advice when they need it. Another common confusion occurs when people assume that their roles automatically endow them with competence: in other words, they think they must be able to supervise simply because someone has asked them to do so. The most pervasive muddle is probably the one surrounding the word supervision itself. For many doctors, the word smacks of hierarchy, monitoring or even policing. They may be perplexed or even critical when they hear that other professionals construe supervision in an entirely different way: as a valuable source of reflection, self-awareness and professionalism.

\section{MAKING A DISTINCTION}

One way that we have found helpful in introducing doctors to a more sophisticated view of supervision is to make a distinction between supervision as they understand it and something we call Super Vision. The different way of spelling the word is arresting. For most people it is self-explanatory as well. They immediately understand that, by a neat linguistic trick, we are drawing attention to the need to turn supervision from the humdrum into something highly desirable, and also visionary. While aspects of technical training and performance monitoring can never be entirely absent from supervision, a focus on Super Vision means that these can be relegated into the background for most of the time in favour of something much more imaginative. The skills needed for this go far beyond telling people what to do. They involve conversational techniques designed to question people about their assumptions, provoke intelligent thinking, and invite continual improvement.

When people first encounter such techniques - especially if they learn that these have been adapted from other professions such as psychology and counselling - they often object that they could not possibly be used in the hurly-burly of an outpatient clinic or ward round, or with trainees who they may barely know because of shift working, rapid job rotations or the other constraints of hospital training nowadays. Surely, they argue, such luxurious approaches to supervision can only make sense in the precious confines of the psychoanalyst's consulting room. Our experience over several years is entirely the reverse. Precise conversational techniques in supervision can be extraordinarily efficient in terms of time and emotion, and can help in even the most pressurised work settings. They can rescue supervisors from having to guide every decision and take the role of "Dr Fixit" in relation to their trainees' problems-something that can be far more demanding than posing a good short question at the right moment. (To take a simple and obvious example, it takes less time to ask "What's your dilemma here...what are your options...what's your hunch is the best option?" than to talk a trainee through half a textbook's worth of unsolicited information.)

\section{CROSS-DISCIPLINARY}

Another advantage of teaching this kind of approach to supervision is that it seems to make sense across all the different medical specialities. On many occasions it even offers a way for consultants and trainees to help each other regardless of technical knowledge. For example, on our courses we regularly watch specialists such as psychiatrists and anaesthetists supervise each other, or other unlikely combinations such as dentists and paediatricians. Although the idea of such crossdisciplinary supervision seems astonishing at first, it really seems quite a natural and obvious possibility once you have seen it in action. Contrary to common assumption, a great deal of supervision doesn't actually involve knowing detailed information about a topic-which the supervisee often knows anyway, or knows how to acquire very easily. Instead, supervision more often needs to address the universals of professional life, crossing all the boundaries of discipline, profession and grade. These include such dilemmas as how to reach ethical decisions, how to 
impart information sensitively to patients and their families, how to respond to complaints, and how to manage tensions within teams. Naivety about the technical content of a case can even be an advantage, as it prevents supervisors from leaping in with premature advice rather than applying their curiosity to help colleagues reach their own decisions.

\section{ROCKET SCIENCE}

I replied to the consultant who thought that supervision wasn't exactly rocket science, explaining why I think that supervision skills are worth at least three days' investment. He sent me a friendly response, although I doubt if we will be seeing him on one of our courses. It is perfectly possibly that he is a wonderful role model to his trainees, inspiring them by his enthusiasm for his speciality and his clinical expertise. He may even be an intuitive conversationalist, knowing how to bring out the best critical thinking in his trainees without having to tell them exactly what to do. But I know that there are many consultants who make the assumption that they are great supervisors, without having asked for systematic feedback from their trainees, or ever subjecting their supervision skills to observation and feedback. I hope that all these doctors will one day learn these skills properly, so they can transform their supervision into Super Vision.

Competing interests: None.

Postgrad Med J 2009;85:335-336.

doi:10.1136/pgmj.2009.082834

\section{Images in medicine}

\section{The catenulaform of neuroblastoma}

A 21-year-old man presented with a 6 month history of pain in both lower extremities and abdomen. There was no family history of note. Examination revealed firm intra-abdominal masses. There were no abdominal scars or hernias and no other specific features. Routine blood tests showed no significant abnormalities. Unenhanced computed tomography (CT) images through the abdomen and pelvis demonstrated five contiguous well defined soft tissue masses lying closely adjacent to the aorta and left common iliac artery in the retroperitoneum, causing some compression of these vessels. The masses were associated with some central amorphous calcification (fig 1A). Following contrast they showed heterogeneous and rim enhancement (fig 1B). Given the distribution of these masses, the differential diagnosis included tumours of neuroendocrine origin, arising from the neural crest of the sympathetic nervous system. The masses were resected at laparotomy and histopathological examination with immunohistochemistry confirmed these to be catenuloform neuroblastomas, given the string-like distribution. The patient made an uneventful recovery.

\section{Y Ma, Y Wang, Z Yang, 0 Gao, Z Cheng, H Qin}

Department of Surgery, the Sixth People's Hospital Affiliated to Shanghai Jiaotong University, Shanghai, China

Correspondence to: Professor H Qin, Department of Surgery, the Sixth People's Hospital Affiliated to Shanghai Jiaotong University, 600 Yishan Road, Shanghai 200233, China; hl-qin@hotmail.com

Funding: This work was financially supported by the grants from Shanghai Science and Technology Development Fund (No.05DJ14010), the Major Basic Research Program of Shanghai (No. 07DZ19505), and the Ministry of Science and Technology of People's Republic of China (No.2008CB517403).

Competing interests: None.

Patient consent: Obtained

Postgrad Med J 2009;85:336. doi:10.1136/pgmj.2008.072736
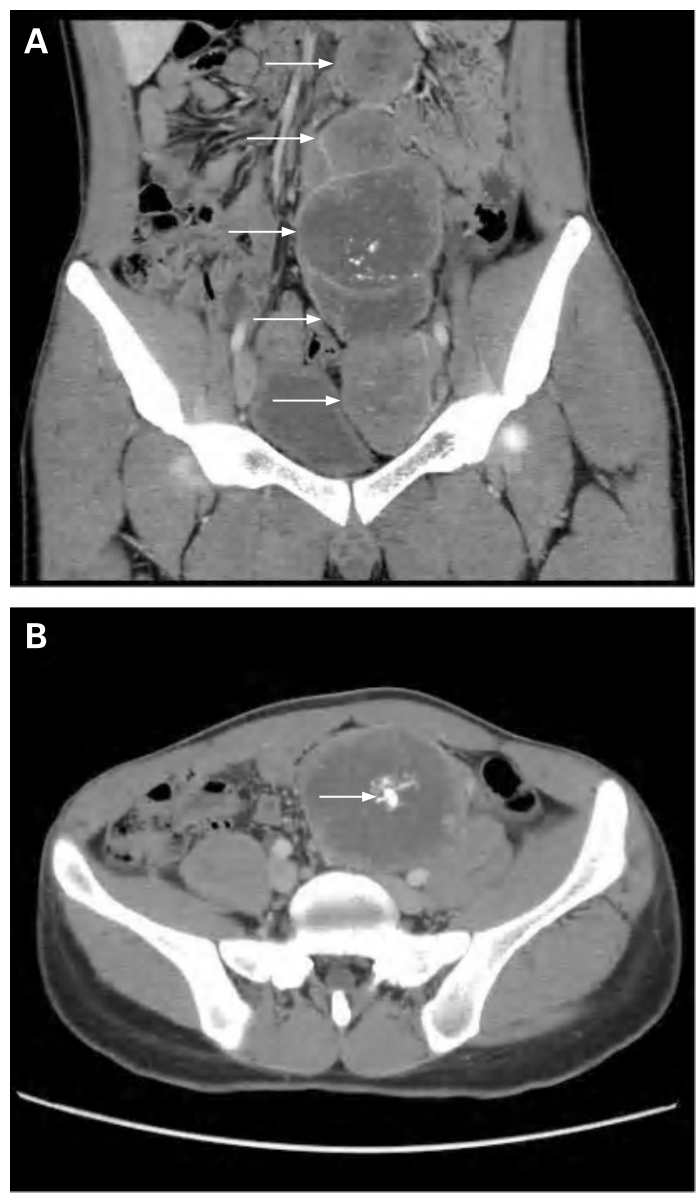

Figure 1 CT images for the catenulaform of neuroblastoma through the abdomen and pelvis. (A) Unenhanced computed tomography images through the abdomen and pelvis demonstrated five contiguous well defined sofe tissue masses lying closely adjacent to the aorta and left commen iliac artery in the retroperitoneum. (B) Contrast computed tomography images showed heterogeneous and rim enhacement for the mass. 